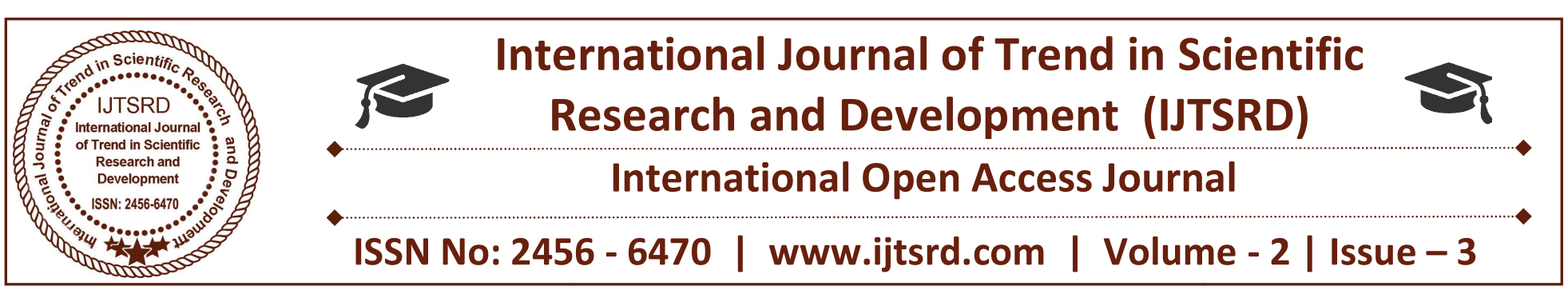

\title{
A comprehensive review on D-FACTS devices
}

\author{
Zeba Akram \\ M.Tech Scholar, Electrical Engineering Department \\ YIET, Gadhauli, Yamunanagar, Haryana, India
}

\section{ABSTRACT}

Flexible ac transmission systems (FACTSs) and voltage-source converters, with smart dynamic controllers, are emerging as a stabilization and power filtering equipment to improve the power quality. Also, distributed FACTSs play an important role in improving the power factor, energy utilization, enhancing the power quality, and ensuring efficient energy utilization and energy management in grids. This paper presents a literature survey of FACTS technology tools and applications for power quality and efficient utilization of electric system. There are some drawbacks of FACTS devices. These drawbacks can be fulfilled by using new compound, scalable, light weighted and cost effective devices that are distributed-FACTS (D-FACTS). D-FACTS controllers are distributed version of conventional lumped FACTS controllers and their cost is low due to lower ratings of component and reliability also increases due to redundancy of devices. The Enhanced Power Flow Controller (EPFC) is a DFACTS controller which is distributed version of thyristor controlled series controller. DPFC controllers are used in series at small distance gap at every 5-10 $\mathrm{km}$ distance with transmission line to control the power flow. This paper discusses extensive review of the DPFC controller and its application in modern power system era.

Keywords: D-FACTS, TCSC, EPFC, FACTS Controller, Power flow control

\section{INTRODUCTION}

Electrical practices for the entire power system industry are tremendously changing and these progressions will mark an evolution of new concepts and strategies in the future, particularly concerning the planning and operation of the power systems. The detrimental effects such as aging, hazardous atmospheric changes associated with conventional energy sources make renewable energy based distributed generation to take a lead in future power generation. Distributed generators like solar, the wind, biomass, fuel cells and microturbines will give significant momentum for power generation in the coming future. A microgrid (MG) is a small scale power network designed for a low voltage distribution system to provide a power supply for a small community/island [1,2]. The microgrid operates in two operating modes; grid connected (connected to the conventional grid to allow power exchange) and individual/islanded mode (independent of the conventional grid). The major elements of $\mathrm{MG}$ have DG units like PV and wind generators, storage devices, different loads, and power controllers. The interconnection of these DGs to the conventional grid is normally achieved by employing power converters. The use of power converters offers vast benefits like optimal operation and flexible control [3]. However, this power electronic interfacing creates a plethora of power quality problems [4-7]. Power quality problems in a microgrid are of a large variety such as voltage harmonics, voltage sags, voltage swells, voltage unbalance, current harmonics, reactive power compensation (RPC), current unbalance and circulation of neutral currents, impulse transients, and interruptions [8]. Among these, reactive power compensation is considered as a major concern in this paper.

The power system operates on AC system and most of the loads used in our daily life demand reactive power. Thus reactive power or VAR compensation is characterized as the administration of reactive energy 
to enhance the performance of the AC system. The issue of reactive power compensation is seen from two ways: load and voltage support. The aim is to achieve an improved power factor and real power balance from the load point of view, while the voltage support is primarily necessary to reduce voltage fluctuations at a given terminal of a transmission or distribution line. In both the cases, the reactive power that flows through the microgrid has to be effectively controlled and compensated.

In islanded operating condition, the microgrid has to maintain the reactive power balance independently due to the absence of an infinite bus. The firmly coupled generation and utilization along with the presence of non-dispatchable intermittent renewable power sources require reactive power support. Similarly, in a grid interconnected mode, the reactive power compensation is also found to be challenging due to linear and non-linear loads. This paper envisages reactive power issues of a microgrid in different conditions. In this regard, a microgrid is modeled and developed consisting of renewable energy sources such as PV and wind energy conversion system (WECS), and connected to a load. Maximum power point tracking (MPPT) controllers are employed for both PV and WECS. The power quality problems of the microgrid, when subjected to supply and load variations, is observed and presented in the next section.

\section{FACTS DEVICES}

FACTS devices and integrated power electronic converters with flexible fast acting control strategies are used in emerging smart grids and integrated ac-dc renewable energy systems. They are based on the concepts of:

i. Modulating apparent admittance (Y) and impedance at the point of common coupling and key common ac bus.

ii. Injecting ac components in series or parallel with the electric network nodes to create current flows or superimposed voltages.

iii. Supplying localized reactive or capacitive current at the bus for reactive power flow control.

iv. Modulating or switching the equivalent-driving point impedance $(Z)$ at the interface bus by controlled switching.
The control strategies are based on voltage, power, angle or reactive power flow control using classical proportional-integral-derivative (PID) controllers, optimal control, heuristic soft computing control strategies and/or a multi-objective control performance index $(\mathrm{J})$. The converter topologies can be classified into:

a) Voltage source-converter fed

b) Dc-current source injection interface

c) Switched/modulated inductors or capacitors

d) Active power filter topologies

The resulting voltage and current waveforms are usually distorted and contain harmonics due to switching nature of power electronics converters, and additional interface filters are usually required. In recent decades, due to the increasing demand of electricity in different countries, the need to build new transmission lines, electricity posts and increase the capacity of transmission lines has greatly increased. But the construction of new electricity transmission lines requires a huge capital investment. As a result, finding effective solutions to reduce the costs for electric companies has been a great challenge. The main objectives of FACTS devices are to increase the useable transmission capacity of lines and to control the power flow over designated transmission routes. FACTS devices are also used to improve the power quality. There are different types of FACTS devices such as static VAR compensator (SVC); dynamic flow controller (DFC); thyristor controlled series compensator (TCSC); HVDC back to back (HVDC B2B); unified power flow controller (UPFC); static synchronous series compensator (SSSC); static synchronous compensator (STATCOM); and dynamic power flow controller (DPFC). According to their connection, they are classified as shunt-connected controllers, series-connected and combined seriesand shunt-connected controllers.

\subsection{Static VAR compensator (SVC)}

In the 1970s, the first generation of FACTS devices, known as Static VAR Compensator (SVC), was introduced. A SVC is a shunt-connected absorber capable of exchanging capacitive/inductive power to control specific parameters of the electrical power system. In 1974, the first SVC was installed in Nebraska by General Electric. More than 800 SVCs with power ratings ranging from 60 to 600 MVAR have been installed by electrical utilities until now. ABB has provided about $55 \%$ of the SVC market, 
with $3 \%$ in Asian countries. SVC may improve transient stability by dynamically supporting the voltage at key points and steady state stability by helping to increasewing oscillation damping. The accuracy, availability and fast response of SVCs enable these devices to provide high performance regarding steady state and transient voltage control. Furthermore, SVCs are used to improve the transient stability, damp power swings and reduce system losses by using reactive power control.

\subsection{Thyristor controlled series compensator (TCSC)}

A TCSC, which consists of a series capacitor bank shunted by a thyristor-controlled reactor to provide a smoothly variable series capacitive reactance. TCSCs play vital roles in the operation and control of power systems such as enhancing power flow, limiting fault current, enhancing transient and dynamic stability. It includes an inductor in parallel with a series capacitor enables a continuous and rapid variable series compensation system. The main advantages of TCSC devices are increased real power transferred, power oscillation damping, sub-synchronous resonance damping and power flow line control. The first TCSC installed in 1992 operates at $230 \mathrm{kV}$ and is used to increase power transfer capability of Kayenta, Arizona Substation. It increased the capacity of the transmission network by nearly $30 \%$. At the end of the year 2004, seven TCSCs were installed around the world such as Stöde/ Sweden, Pinguo substation in 1999, State power south company, Guangzhou/China in 2002 and Raipur substation/ India in 2004. A TCSC has three operation modes:

(i) thyristors blocked (no gating and zero thyristor conduction), where the TCSC net impedance is just the capacitive reactance,

(ii) thyristors activated (continuous gating and full thyristor conduction), where most of the line current flows through the inductive reactance, and

(iii) Vernier operation with phase control of gating signals. In the last mode, the thyristors are controlled in such a manner that a certain amount of inductive current can circulate through the capacitor, thereby increasing the effective capacitive/inductive reactance of the module.

\subsection{Static synchronous compensator (STATCOM)}

A STATCOM is integrated by a SVC usually based on the gate turnoff (GTO) type thyristors. The STATCOM is capable of generating or absorbing reactive power at its output terminals. It can also deal with real power when it is fed from an energy source or an energy storage device of appropriate rating. The first STACTOM was installed in Japan in 1991. It is rated at \pm 80 MVAR and provides voltage stabilization in Inumaya substation. The largest STACOMSs with a capacity of $+225 \mathrm{MVAR}$ and \pm $100 \mathrm{MVAR}$ were installed in East Claydon $400 \mathrm{kV}$ substation/UK in 2001 and SDG \& E Talega substation/USA in 2003, respectively. The purposes of those STATCOMs installations were to provide dynamic reactive compensation of East Claydon 400 $\mathrm{kV}$ substation, and dynamic VAR control during peak load conditions of SDG \&E Talega substation. Also, in 2013 a STATCOM with capacity of \pm 150 MVAR at $275 \mathrm{kV}$ was installed in Turnkey too.

\subsection{Static synchronous series compensator (SSSC)}

A SSSC is an FACTS controller based on a seriesconnected VSC. It injects a voltage with controllable magnitude and phase angle at the line frequency and is found to be very capable of handling power flow control, besides improving transient stability margin and transient damping. The main advantage of SSSC over a TCSC is that it does not remarkably affect the impedance of the transmission system and hence there is no danger of having resonance problems.

\subsection{Distributed FACTS (D-FACTS)}

Due to the increasing use of RESs as DG in the electrical distribution network, the policy of investment in the energy area and control of power system has changed. It is a new concept of D-FACTS was suggested as an alternative solution to solve the main problem of the last generation of FACTS devices, which is the cost effective power flow control. Currently, D-FACTS are designed to address power control types of problems. D-FACTS can be used to dynamically control the effective line impedance. Also, from a power system perspective, D-FACTS devices offer many potential benefits since they are less expensive and smaller than usual FACTS devices, which may make them better candidates for wide scale deployment. The most important DFACTS that have been used in the smart/ micro grids. Nowadays, increasing performance and decreasing price of power electronics and communication technologies is transforming the entire electrical industry sectors into modern electrical networks. Deployment of low power FACTS devices, i.e. DFACTS devices, can provide a higher performance and lower cost method for enhancing smart/micro 
grids controllability and reliability, enhancing asset utilization and end-user power quality, while environmental impact and minimizing system cost.

\section{FACTS/D-FACTS devices and power quality}

Use of RESs in traditional electrical networks has changed the policy of electrical utilizes regarding control, reliability, management, power quality and protection of electrical system. Good power quality is an important factor for a reliable supply of electricity to loads in a power system. However, the current electronic devices and nonlinear loads produce nonsinusoidal waveforms, which can result in poor power quality. FACTS and D-FACTS devices play an important role to enhance power quality in traditional (without RES) and modern (with RES) electrical networks. Energy management by fuzzy logic controllers.

\section{Role of FACTS devices in improving power quality in future networks}

Emerging smart grids with DG, including RESs, and integration of ac-dc systems require the use of FACTS devices and stabilization power electronic converters, together with fast acting control strategies. New FACTS topologies are emerging to ensure decoupled ac-dc interface, improved voltage security, reactive compensation, voltage and power factor improvement, and loss reduction. They also enhance the security of micro grids, stand-alone ac-dc DG schemes using photovoltaic, wind, fuel cell, battery storage, micro gas turbines (MGT), wave/tidal generation $\mathrm{CNG} /$ diesel GEN-sets as back-up systems. FACTS technology includes VSCs, STATCOMs, SSSCs, UPFs, active power filters and GateControlled Series Capacitor (GCSC). Modern power systems with new demand smart metering (DSM) and integrated DG including solar PV and wind farms will require new modified smart-soft computing, control strategies and enhanced power electronic converter topologies to ensure reliability, security, power quality and efficient utilization without transient overvoltages and inrush currents. Improved energy utilization with effective voltage regulation at key interface bus regulations will restrict sizing/ siting of distributed renewable/alternate generation. Green and renewable energy generation are expected to supply $20-25 \%$ of the electrical energy by 2050 from sources that include the wind, solar, geothermal, wave/tidal, bio/natural gas, fuel cell, hybrid, and waste to energy. Also, new designs of flexible VSC FACTS schemes will target distribution/utilization network devices such as the distributed static series compensators (DSSCs), distribution STATCOMs (DSTATCOMs) and switched power filters compensation schemes.

\section{CONCLUSIONS}

This paper has presented a comprehensive overview of use of FACTS/D-FACTS technology and its application in emerging electric utilities using RESs with power electronic converters. The existing FACTS devices are undergoing tremendous changes in configurations based on soft computing control strategies using smart grid-based fast control strategies and the multi-functional use of voltage control, stabilization, reactive power compensation and unified power flow control. The paper has presented FACTS based solutions and a list of control strategies to deal with the extensive use of nonlinear/sensitive loads, renewable energy sources, battery storage and EV-charging. Suitability and adequacy of the FACTS devices such as SVC, DSTATCOM, SSSC and APFs as well as LC switched compensators have been presented. The emphasis of the presented analysis is on energy efficient utilization, loss reduction, voltage stabilization, power factor, power quality and harmonic reduction at the point of common coupling with nonlinear loads. Also, other issues, including interfacing wind/PV farms with weak ac electric utility systems were considered. Future applications of FACTS devices include renewable energy resources, residential and commercial smart building, residential use of hybrid DC-AC grid, increased use of vehicles-to-grid and vehicles-tohouse, battery charging system, and street, buildings and airports light emitting diode (LED) lighting technology.

\section{REFERENCES}

1. Kalair A, Abas N, Kalair AR, Saleem Z, Khan N. Review of harmonic analysis, modeling and mitigation techniques. Renew Sustain Energy Rev 2017;78(10):1152-87.

2. Martínez EB, Camacho CÁ. Technical comparison of FACTS controllers in parallel connection. J Appl Res Technol 2017;15(1):3644.

3. Jumaat SA, Musirin I, Baharun MM. A voltage improvement of transmission system using static var compensator via matlab/simulink. Indones $\mathrm{J}$ Electr Eng Comput Sci 2017;6(2):1-17.

4. Fadaee M, Radzi MAM. Multi-objective optimization of a stand-alone hybrid renewable 
energy system by using evolutionary algorithms: a review. Renew Sustain Energy Rev 2012;16(5). [3364-2269].

5. Sadaiappan S, Renuga P, Kavitha D. Modeling and simulation of series compensator to mitigate power quality problems. Int J Eng Sci Technol 2010;2(12):7385-94.

6. Liu L, Li H, Xue Y, Liu W. Reactive power compensation and optimization strategy for gridinteractive cascaded photovoltaic systems. IEEE Trans Power Electron 2015;30(1):188-202.

7. Darabian M, Jalilvand A. A power control strategy to improve power system stability in the presence of wind farms using FACTS devices and predictive control. Int J Electr Power Energy Syst 2017;85(2):50-66.

8. Sharaf AM, Gandoman FH. A switched hybrid filter - DVS/green plug for smart grid nonlinear loads, in Smart Energy Grid Engineering (SEGE), 2015 IEEE International Conference on; 17-19 Aug. 2015. p. 1-6.

9. Sharaf AM, Khaki B. Novel switched capacitorfilter compensator for smart gridelectric vehicle charging scheme, in Proc. IEEE SGE, Oshawa, Canada; Aug 2012.p. 1-6.

10. Abdelsalam AA, Desouki ME, Sharaf AM. Power quality improvement using FACTS power filter compensation scheme. J Electr Syst 2013;9(1):8696.

11. Mahela OP, Shaik AG, Gupta N. A critical review of detection and classification of power quality events. Renew Sustain Energy Rev 2015;41:495505.

12. Velamuri S, Sreejith S. Power flow analysis incorporating renewable energy sources and FACTS devices. Int $J$ Renew Energy Res 2017;7(1):452-8.

13. Crow ML. Power quality enhancement using custom power devices. IEEE Power Energy Mag 2004;2:50.

14. Subasri CK, Charles Raja S, Venkatesh P. Power quality improvement in a wind farm connected to grid using FACTS device. Power Electron Renew Energy Syst 2015;326(4):1203-12.

15. Dugan RC, Mc Granaghan MF, Santoso S, Beaty HW. Electrical power systems quality. 2nd edition
New York, USA: Mc Graw-Hill Professional Engineering Series; 2003.

16. Liao H, Milanović JV. On capability of different FACTS devices to mitigate a range of power quality phenomena. IET Gener Transm Distrib 2017;11(5):2002-12.

17. Wang X, Blaabjerg F, Wu W. Modeling and analysis of harmonic stability in an ac powerelectronics-based power system. IEEE Trans Power Electron 2014;29(12):6421-32.

18. Chen Z, Spooner E. Grid power quality with variable speed wind turbines. IEEE Trans Energy Convers 2001;16(5):148-54

(1)

S

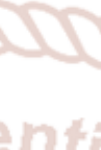

